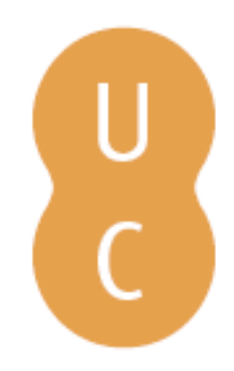

\title{
pompalina
}

\section{A mídia em foco: exemplos de desinformação climática}

Autor(es): $\quad$ Nunes, Lucí Hidalgo; Zamparoni, Cleusa Aparecida Gonçalves Pereiza

Publicado por: Imprensa da Universidade de Coimbra; RISCOS - Associação

URL

persistente: URI:http://hdl.handle.net/10316.2/34805

DOI: $\quad$ DOI:http://dx.doi.org/10.14195/978-989-96253-3-4_13

Accessed : $\quad$ 26-Apr-2023 10:47:30

A navegação consulta e descarregamento dos títulos inseridos nas Bibliotecas Digitais UC Digitalis, UC Pombalina e UC Impactum, pressupõem a aceitação plena e sem reservas dos Termos e Condições de Uso destas Bibliotecas Digitais, disponíveis em https://digitalis.uc.pt/pt-pt/termos.

Conforme exposto nos referidos Termos e Condições de Uso, o descarregamento de títulos de acesso restrito requer uma licença válida de autorização devendo o utilizador aceder ao(s) documento(s) a partir de um endereço de IP da instituição detentora da supramencionada licença.

Ao utilizador é apenas permitido o descarregamento para uso pessoal, pelo que o emprego do(s) título(s) descarregado(s) para outro fim, designadamente comercial, carece de autorização do respetivo autor ou editor da obra.

Na medida em que todas as obras da UC Digitalis se encontram protegidas pelo Código do Direito de Autor e Direitos Conexos e demais legislação aplicável, toda a cópia, parcial ou total, deste documento, nos casos em que é legalmente admitida, deverá conter ou fazer-se acompanhar por este aviso.

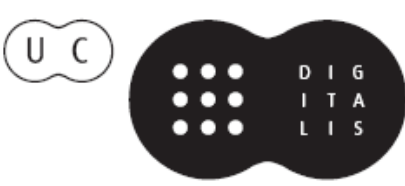



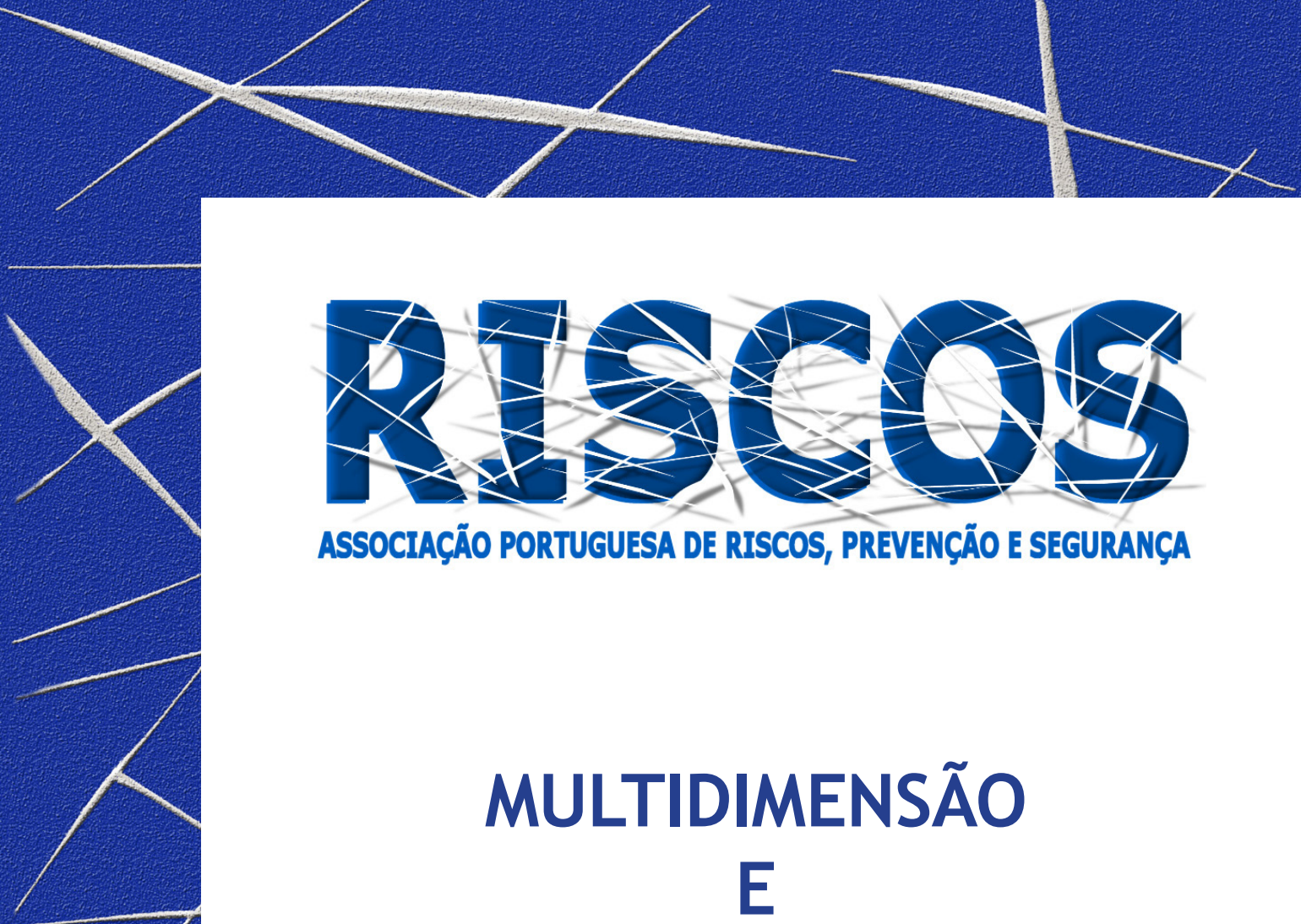

ASSOCIAÇÃO PORTUGUESA DE RISCOS, PREVENCCÃO E SEGURANÇA

MULTIDIMENSÃO

E
TERRITÓRIOS DE RISCO

III Congresso Internacional

I Simpósio Ibero-Americano

VIII Encontro Nacional de Riscos

Guimarães

2014 


\title{
A MÍDIA EM FOCO: EXEMPLOS DE DESINFORMAÇÃO CLIMÁTICA
}

\author{
Lucí Hidalgo Nunes \\ Departamento de Geografia, Universidade Estadual de Campinas, Brasil \\ luci@ige.unicamp.br
}

Cleusa Aparecida Gonçalves Pereiza Zamparoni Depatamento de Geografia, Universidade Federal de Mato Grosso, Brasil cazamp@gmail.com

\begin{abstract}
RESUMO
A mídia desempenha relevante função na formação de opinião pública sobre os mais diferentes temas, o que reforça seu papel central na sociedade democrática; porém, nem sempre a informação é repassada de forma adequada. Tal fato é particularmente relevante no caso de informações de caráter climático, estratégicas para uma série de condutas que norteiam ações específicas no território e que apresentam potencial para prevenir acidentes e perdas econômicas e/ou de vidas humanas. Ocorre que entre sua origem e seu receptor a informação, intermediada pela mídia, pode sofrer distorções, simplificações, inconsistências e erros, comprometendo seu uso. Foram avaliadas diversas notícias disseminadas de forma equivocada sobre fenômenos atmosféricos veiculadas em diferentes mídias e em distintos períodos. Em geral as notícias foram confusas, contraditórias, erradas, simplistas, alarmistas e sensacionalistas, podendo ter induzido a mal entendidos ou mesmo descrença e desinteresse pela temática. Com isso, a mídia falhou em sua importante função social, tanto como elemento-chave na tomada de medidas preventivas ou soluções mais eficientes para minorar as consequências de futuros episódios, como em sua função educativa, mais desinformando do que propriamente informando o leitor.
\end{abstract}

Palavras-chave: mídia, sensacionalismo, clima

\section{Introdução}

Os assuntos relacionados ao tempo e ao clima abarcam dimensões socioambientais, espaciais e econômicas, levantando interesse da sociedade e, assim, ocupando espaço crescente na imprensa. As informações veiculadas incluem não apenas a previsão do tempo, mas também a associação de algumas condições atmosféricas a aspectos relevantes, como saúde, agricultura, esporte, lazer, política e economia. Questões científicas como informações sobre mudanças climáticas e outros assuntos de natureza ambiental têm também ganhado maior projeção nas diferentes mídias, conforme alertam Weingart et al. (2000). Schäffer e colegas (2013) lembram que em alguns momentos esses assuntos recebem ainda maior atenção, como no período das reuniões anuais sobre as mudanças do clima (International Climate Summit). Esse mesmo fato foi observado por Zangalli Jr. (2013), que notou que em 2001 e 2007, anos em que foram divulgados dois dos relatórios produzidos pelo IPCC (Painel Intergovernamental sobre Mudanças do Clima), houve número maior de notícias sobre esse assunto em periódicos brasileiros.

As mídias podem ser classificadas seguindo diferentes critérios como, por exemplo, de acordo com a frequência (diária, no caso de jornais; semanal, quinzenal ou mensal, no caso de revistas, ou ainda mais rápida, com conteúdos constantemente atualizados, no caso de sítios da internet), com a abrangência (local, regional, nacional) ou mesmo de acordo com a qualidade da informação, tendo em vista que alguns veículos de comunicação são claramente sensacionalistas. No entanto, mesmo no caso de fontes de informação mais sérias e comprometidas com a qualidade, não chega a ser incomum a publicação de notícias apelativas, cujos propósitos são muito mais chamar a atenção do que realmente informar, inclusive nos assuntos relativos às situações do tempo e do clima. 
Abordando essa temática, Carvalho (2007) assinala um paradoxo criado pela mídia, ao difundir informações contrastantes: a autora exemplifica esse fato a partir de um periódico britânico, cujas notícias alertam quanto aos riscos das mudanças climáticas e a necessidade de ação com base em pesquisas científicas, mas igualmente veicula propagandas pagas de corporações que contribuem para agravar esse problema. Nesses casos fica patente, também, que a imprensa abdica da função social de ser um elemento-chave na articulação de assuntos centrais na contemporaneidade e na formação da cidadania consciente. Por sua vez, Liedtike (2003) assevera que na lógica liberal a finalidade de lucro suplantaria as educativas e culturais nos meios de comunicação.

Considerando que as condições atmosféricas são complexas e centrais no cotidiano, e que a mídia é o principal canal para obter informações acerca desses assuntos para a grande maioria da população, a qualidade e até a ênfase na construção do discurso são elementos de enorme relevância. Tendo isso em vista, o objetivo desta pesquisa foi examinar a disseminação da informação de natureza atmosférica pela imprensa, avaliando alguns exemplos brasileiros.

\section{Análise da qualidade da informação climática a partir de alguns exemplos da mídia brasileira}

Imprecisões e erros na veiculação de notícias sobre fenômenos atmosféricos podem ter diversas origens e intencionalidades, sendo que os exemplos que seguem se atrelam a alguns dos tipos de inconsistências identificados. Foram consultadas as seguintes fontes: jornais $\mathrm{O}$ Estado de $\mathrm{S}$. Paulo e Folha de MT, Revista Veja (semanário de alcance nacional) e a mídia online www. gazetadigital.com.br.

- reportagens muito breves, sem maiores referências e com simplificações e dubieidades que podem conduzir o leitor a interpretações parciais da realidade. Ex. (reportagem publicada em 1 de novembro de 2008, Jornal O Estado de S.Paulo): “Água devasta 30 km de floresta” - tratou-se de notícia acerca do rompimento de uma barragem, mas não houve esclarecimentos da causalidade (chuvas intensas, erros técnicos na construção ou outros);

- falta de explicação de informações derivadas de estudos científicos, comprometendo o entendimento do conteúdo. Ex. (notícia publicada em 31 de janeiro de 2008, Jornal 0 Estado de S.Paulo): "Aquecimento da água em $0,5^{\circ} \mathrm{C}$ aumenta furacões" - a informação reportava um evento registrado em setor do Atlântico Norte ocidental; porém, a falta de elucidação pode ter induzido o leitor ao raciocínio de que a partir de qualquer temperatura o incremento de $0,5^{\circ} \mathrm{C}$ propicia a formação dessa perturbação atmosférica;

catastrofismo. Ex.1 (manchete publicada em 1 de fevereiro de 2008, Jornal 0 Estado de S.Paulo): “Aquecimento vai piorar fome até 2030" - o assunto é tratado como uma sina da qual não há escapatória, não discorrendo quanto a outras formas de combater a fome e imputando apenas a uma causalidade (climática) essa questão complexa. Ex.2 (reportagem publicada em 13 de setembro de 2008, Jornal O Estado de S.Paulo): “Furacão Ike: 'É fugir ou morrer', alerta Texas” - além do título chamativo, paira a dúvida, não dirimida ao ler a notícia inteira de quem estaria alertando, visto que Texas é um estado norte-americano; Ex.3 (edição de 21 de junho de 2006, Revista Veja): "Aquecimento global: os sinais do apocalipse" - reportagem de capa, ilustrada com a imagem de um urso polar - animal que vem sendo um ícone desse assunto - mescla abordagem mais comedida, com informações geradas por pesquisas empreendidas por cientistas de diferentes áreas do conhecimento, nações e centros de excelência, com termos sensacionalistas e exagerados; 
abordagem superficial, desconexa e descompromissa. Ex.1 (reportagem publicada em 31 de agosto de 2014, Jornal A Gazeta de Cuiabá/MT) “Clima seco dissemina doenças contagiosas" além do conceito de clima ter sido utilizado para se referir ao tempo, no contexto da estação de inverno (estação seca) em Cuiabá/MT, a notícia apresenta relação direta da estação seca com as doenças contagiosas, não considerando problemas de gerenciamento da saúde local, acrescido da tendência de elevação das temperaturas acompanhadas de baixas porcentagens de umidade relativa derivadas das modificações no uso da terra, em especial aquelas que se atrelaram a obras de mobilidade urbana motivadas pela recente Copa do Mundo de 2014;

- 'demonização' de fenômenos atmosféricos: Ex (manchete publicada em 12 de maio de 2008, Jornal O Estado de S.Paulo): "Natureza em fúria: num único dia 34 tornados afligem os EUA" - adjetivação de fenômenos naturais com expressões que colocam a natureza como raivosa, vingativa e revanchista;

informações erradas. Ex1 (manchete publicada 17 de setembro de 1997, Jornal O Estado de S.Paulo): "O fenômeno" - no corpo da reprtagem aparece a seguinte afirmação: "O fenômeno, conhecido como El Niño, provoca graves alterações no clima mundial” - na verdade, esse processo afeta temporariamente as condições de tempo em locais do globo sob sua influência, sendo, assim, um componente do clima desses setores. Ex. 2a, 2b e $2 \mathrm{c}$ (manchetes publicadas em 05 de janeiro de 2008 e em 22 de junho de 2012, O Estado de S.Paulo, e em 22 de julho de 2014, Folha do Estado de MT ): "Festival do gelo é prejudicado por clima quente", "Clima no Brasil faz preço do café disparar em NY" e "O clima na Capital começa a voltar ao normal na terça-feira (29)" - nos tres casos o termo correto é tempo e não clima, já que as notícias se referem a condições específicas e momentâneas: esse é um erro muito recorrente na imprensa brasileira. Ex.3 (manchete publicada em 27 de agosto de 2012, no sítio www. gazetadigital.com.br) “Massa de ar frio derruba temperatura” - neste caso, foi uma frente fria, derivada de chuvas frontais, já que a massa de ar frio quando atinge Cuiabá/MT, vem formando frentes com as massas de ar quentes sempre presentes nesta localidade. Além disso, a utilização da terminologia "derruba" remete à pretensa perversidade da força da natureza. Ex.4 (manchete publicada em 22 de julho de 2014, Folha do Estado de MT) - "Termômetros só voltam a subir na segunda-feira (28)" termômetros não sobem, mas a temperatura se eleva;

falta de contextualização e conexões entre causas e responsabilidades. Ex. 1 (manchete publicada em 04 de setembro de 2014, Diário de Cuiabá): “Chuva, estragos e susto” - a reportagem atribui às chuvas a responsabilidade pelos problemas de ordem estrutural que ocorreram em vários pontos da cidade, inclusive no aeroporto local.

Outras práticas tendenciosas e que não contribuem para a disseminação de informação de boa qualidade podem ser elencadas: nações de maior projeção no cenário internacional ou mesmo regiões mais ricas de um país recebem maior atenção da mídia em qualquer tipo de informação, inclusive as de natureza atmosférica, fato assinalado por Nunes (2007 e 2009) e Carvalho (2007), que sublinha que notícias sobre áreas mais periféricas dos grandes centros de decisão somente aparecem quando há registro de desastres naturais ou induzidos pela ação humana, exemplificando com o continente africano. Na mesma linha, Weingart et al. (2000) asseveram que a propagação das notícias projeta preferências e prioridades dos grupos dominantes e influenciam percepções individuais e coletivas, bem como decisões políticas. Outro aspecto a ressaltar é que muitos assuntos ganham relevância em alguns momentos, mas passado algum tempo não há continuidade, de maneira que o leitor não sabe o desfecho do assunto: esse fato é muito presente quando acontece alguma catástrofe natural. 


\section{Conclusão}

Além do papel óbvio da imprensa, que é ser informativa, o jornalismo tem potencial para desempenhar inúmeras funções vitais na sociedade contemporânea, com destaque para seu caráter educacional, sociocultural e político, formador de opinião e influenciador de decisões políticas relevantes para a sociedade.

As informações de caráter climático conjugam aspectos atraentes para o público leitor, como possibilidade de previsão de acontecimentos, projeções de cenários possíveis e planejamento de ações em diferentes prazos, o que as tornam cada vez mais presentes nas diversas mídias, divulgadas à luz de enfoques distintos. Contudo, faz-se necessário avaliar como as informações são passadas ao público e como elas são (ou não são) incorporadas a novas práticas e pensares. Esta pesquisa se propôs a examinar o primeiro desses aspectos, trazendo alguns exemplos de reportagens publicadas em mídias brasileiras que têm como proposta serem mais do que meramente informativas, serem formadoras de opinião.

Os exemplos são muitos, mas nos exemplos usados neste estudo destacam-se erros conceituais, ausência de explicações e conexões, exageros, termos inadequados e com caráter claramente sensacionalista.

Assinala-se que se de um lado a informação sobre tempo e clima é cada vez mais presente, por outro a forma como ela tem sido divulgada não contribui, necessariamente, para um conhecimento mais preciso dos fenômenos atmosféricos, que estão entre os que mais diretamente influenciam a vida das pessoas. Além disso, a disseminação de informações fidedignas cumpriria o papel de colaborar na construção da cidadania e informar os tomadores de decisão acerca da importância dessas questões para a construção de locais mais saudáveis e seguros, fatos que ao menos parte da imprensa brasileira não tem tido papel proativo.

\section{Bibliografia}

Carvalho, A. (2007) - Communicating global responsibility? Discourses on climate change and citizenship. International Journal of Media and Cultural Politics v.3 (2), Commentaries. Intellect Ltd, Bristol, UK, p. 180-183.

Liedtke, P.F. (2003) - Políticas públicas de comunicação e o controle da mídia no Brasil. Tese - Revista Eletrônica dos Pós-Graduandos em Sociologia Política da UFSC, v.1, (n¹). UFSC, Santa Catarina, p. 39-69.

Nunes, L.H. (2007) - O papel da mídia na difusão da informação climática: o El Niño de 1997-98. Geografia, Rio Claro, 32, p.29-50.

Nunes, L.H. (2009) - Media Communication of Extreme Events: A Case Study for Brazil. European Conference on Severe Storms, $5^{\text {th }}$. Landshut, Germany. 2p. Disponível em: <https://www.essl.org/ECSS/2009/ preprints/011-3-nunes.pdf>

Schäffer, M.S.; Ivanova, A.; Schmidt, A. (2013) - What drives media attention for climate change? Explaining issue attention in Australian, German and Indian print media from 1996 to 2010. International Communication Gazette. v.76 (2), Sage Publications, p.152-176.

Weingart, P.; Engels, A.; Pansegrau, P. (2000) - Risks of communication: discourses on climate change in science, politics, and the mass media. Public Understanding of Science, v. 9, Sage Publications, p. 261-283.

Zangalli Jr., P.C. (2013) - Entre a ciência, a mídia e a sala de aula: contribuiç̃oes da geografia para o discurso das mudanças climáticas. Presidente Prudente: FCT, UNESP. Dissertação (Mestrado), 148 p. 